\title{
On the Anionic Group Approximation to the Borate Nonlinear Optical Materials
}

\author{
Rukang Li ${ }^{1,2}$
}

1 Beijing Centre for Crystal Research and Development, Key Laboratory of Functional Crystals and Laser Technology, Technical Institute of Physics and Chemistry, Chinese Academy of Sciences, Beijing 100190, China

2 University of Chinese Academy of Sciences, Beijing 100049, China; rkli@mail.ipc.ac.cn

Academic Editors: Ning Ye and Helmut Cölfen

Received: 25 January 2017; Accepted: 8 February 2017; Published: 11 February 2017

\begin{abstract}
In this mini-review type of article, a brief summary of the anionic group approximation as it relates to the borate nonlinear optical (NLO) crystals, an idea firstly proposed by Professor Chen, is presented. The basic idea, calculation method, tabulated coefficients of various common borate, as well as nitrate or carbonate groups, in their ideal geometries will be presented. New practices reveal that those parameters can still give very accurate predicted NLO coefficients for recently found NLO crystals without any adjustment of parameters.
\end{abstract}

Keywords: nonlinear optical; borates; structure-property relations; semi-classical calculation

\section{Introduction}

Just one year after the first laser was demonstrated, the nonlinear optical (NLO) effect was observed in the $\mathrm{SiO}_{2}$ crystal [1]. The next decade saw the first burst era of new NLO crystals with the findings of some now well-known NLO materials, e.g., KDP, AgGaS $, \mathrm{ZnGeP}_{2}, \mathrm{LiNbO}_{3}, \mathrm{LiIO}_{3}$, urea, etc. [2-5]. Through nonlinear optical processes, such as second harmonic generation (SHG), sum frequency generation (SFG) or optical parametric chirped pulse amplification (OPCPA), NLO materials can expand the laser wavelength to a much greater range from UV to far-IR and even the THz range, help to reduce the laser peak width to a femto-second or even an atto-second time frame, and can increase the laser peak power to the petawatt level. At the same time, great efforts were also devoted to the understanding of the structure-property relations of those new materials, though the microscopic basic mechanism at the quantum mechanics level [6] of the NLO property was known just one year after the NLO effect was found,

$$
\begin{aligned}
\beta_{i j k}^{2 \omega}=\frac{e^{3}}{2 \hbar^{2}} \sum_{n, n^{\prime}} \quad & \left\langle g\left|r_{i}\right| n\right\rangle\left\langle n\left|r_{j}\right| n^{\prime}\right\rangle\left\langle n^{\prime}\left|r_{k}\right| g\right\rangle \frac{1}{\left(\omega_{n g}+2 \omega\right)\left(\omega_{\left.n^{\prime} g\right\rangle}+\omega\right)}+ \\
& \left\langle g\left|r_{j}\right| n^{\prime}\right\rangle\left\langle n^{\prime}\left|r_{k}\right| n\right\rangle\left\langle n\left|r_{i}\right| g\right\rangle \frac{1}{\left(\omega_{n g}-2 \omega\right)\left(\omega_{n^{\prime} g}-\omega\right)}+ \\
& \left.\left\langle g\left|r_{k}\right| n\right\rangle\left\langle n\left|r_{i}\right| n^{\prime}\right\rangle\left\langle n^{\prime}\left|r_{j}\right| g\right\rangle \frac{1}{\left(\omega_{n g}-\omega\right)\left(\omega_{n^{\prime} g}+\omega\right)}\right\}
\end{aligned}
$$

where $\beta_{i j k}^{2 \omega}$ is the SHG coefficient, which is a special case of the second-order susceptibilities when the incident beams involved are at the same frequency $\left(\omega=\omega_{1}=\omega_{2}\right)$. All the other symbols in the above equation take their usual meanings. Due to the lack of high-performance computers, semi-classical approximations to the materials had to be made. The three most successful ones were: the double-level or single oscillator model, the bond-parameter model and the charge transfer model [7-9]. The single 
oscillator model simplifies the energy levels in a crystal to just two levels and if the optical wavelength is far from resonance, then Equation (1) reduces to:

$$
\beta_{i j k}^{2 \omega}=\frac{e^{3}}{2 \hbar^{2}}\left\{\left\langle g\left|r_{i}\right| n\right\rangle\left\langle n\left|r_{j}\right| n\right\rangle\left\langle n\left|r_{k}\right| g\right\rangle \omega_{n g}^{-2}+\ldots\right\}
$$

Such an approximation was applied to the crystals with diamond-type and zinc blend-type structures and satisfactory SHG coefficients for both value and parity were obtained [7]. However, this model actually neglects all the contributions of the triple energy level systems; in some materials such approximation is not allowed, hence wrong results were found using this model. The more successful model is the bond-charge model developed by Levine and others [8]; this model proposed that the polarizabilities of both the first (related to refractive indices) and second order (related to electro-optical and SHG coefficients) can be divided into the contributions of individual chemical bonds. By definition of series of bond parameters, this model could obtain SHG coefficients with $20 \%$ accuracy for most of the $\mathrm{NLO}$ crystals found at the time, including $\mathrm{AB}_{2}, \mathrm{ABC}_{2}, \mathrm{ABC}_{4}$ and $\mathrm{LiNbO}_{3}, \mathrm{LiTaO}_{3}$, $\mathrm{Ba}_{2} \mathrm{NaNb}_{5} \mathrm{O}_{15}$. Nevertheless, this model still failed to account for the NLO coefficients of crystals with strongly anisotropic bonds, e.g., $\mathrm{NaNO}_{2}$, urea, $\mathrm{LiCHO}_{2} \cdot \mathrm{H}_{2} \mathrm{O}$, and needed more parameters for crystals containing distorted $\mathrm{MO}_{6}$ octahedral anionic groups. The third successful model was the charge transfer model proposed by Davidov et al. [10] and developed by Oudar and Chemla [11]. This model treats the organic NLO compounds with a long $\pi$-conjugated system; when an electron transitions in a molecule accompanied by large changes of the dipole moment, large second-order susceptibility will be observed. In addition, it was found that molecules with donor and acceptor functional groups just fulfil such conditions and organic crystals with large NLO coefficients were found, e.g., MNA, POM and NPP [12]. This model still plays a role in the recent findings of organic crystals of DAST, DMTS, etc., which are suitable for the generation of $\mathrm{THz}$ radiations.

Taking into consideration the successes and failures of the bond-charge model, Prof. Chen in the mid-1970s proposed that the anionic groups rather than the individual chemical bonds should be considered as the basic structural units for the generation of the nonlinear optical effects [13-15]. Calculations on the crystals with distorted octahedral $\mathrm{MO}_{6}$ units showed that such a model gave a perfect fit to the experimental results $[16,17]$.

\section{Results}

When I first entered this field as a postgraduate student in 1982, Prof. Chen directed me towards applying the quantum chemical calculation method to the borate system specifically to understand the exact mechanism of the nonlinearity of the newly found, now-famous $\mathrm{BBO}\left(\beta-\mathrm{BaB}_{2} \mathrm{O}_{4}\right)$ [18]. Borrowing a FORTRAN code of the CNDO (Complete Neglecting of Differential Overlap) program [19] from a neighbouring quantum chemistry group at the Fujian Institute on the Structure of Matter, I started to modify the original code of the CNDO and to program new subroutines applicable to calculate the second-order susceptibility based on Equation (1). After about half a year of frustrating and difficult work on checking the original and newly programmed FORTRAN codes sentence by sentence, the correct results showed up at the end of 1983 and the first ever paper on the calculation of the NLO properties of the borate crystal ( $\beta-\mathrm{BBO})$ was published in 1985 [20]. The calculation showed that the large nonlinearity of the $\beta$-BBO crystal comes solely from the anionic $\left[\mathrm{B}_{3} \mathrm{O}_{6}\right]^{3-}$ group, whereas the contribution from the cation $\mathrm{Ba}^{2+}$ can be completely neglected. The macroscopic NLO coefficients can be obtained by the geometric superposition of the second-order susceptibilities of the $\left[\mathrm{B}_{3} \mathrm{O}_{6}\right]^{3-}$ groups in the crystal unit cell with the following equation:

$$
d_{I J K}^{2 \omega}=\frac{S_{I J K}}{V} \sum_{i j k, g} T_{I i} T_{J j} T_{K k} \beta_{i j k}^{2 \omega}(g)
$$


where $V$ is the unit cell volume, $T_{I i}, T_{J j}, T_{K k}$ are the direction cosines of the local Cartesian axes of individual anionic group to the crystal axes, and $S_{I J K}$ is the local field correction factor which can be obtained from refractive indices as: $S_{I J K}=\frac{n_{I}^{2}+2}{3} \cdot \frac{n_{J}^{2}+2}{3} \cdot \frac{n_{K}^{2}+2}{3}$.

After the success of the calculation of the BBO crystal, Wu Yicheng, another student (Doctoral) of Prof. Chen, who then worked on the synthesis and growth of yet another famous $\mathrm{LiB}_{3} \mathrm{O}_{5}$ (LBO) crystal, joined in. After calculations of various commonly found anionic groups in the borate crystals, we published a series of papers on the application of anionic group approximation to the development of NLO borate crystals [21-23]. Afterwards, we extended the calculation to real materials: The SHG coefficients of $\mathrm{LiB}_{3} \mathrm{O}_{5}$ and $\mathrm{CsB}_{3} \mathrm{O}_{5}(\mathrm{CBO})$ were calculated before the measured values could be obtained [24]. The calculation actually helped the orientation settings for the measurements and the determination of the relative signs of the measured coefficients of LBO [24]. The measurements on $\mathrm{CBO}$ came four years later, after the publication of the calculated results, when a large-enough crystal was obtained finally [25]. However, it should be noted that the above calculations all took the geometries of the individual borate groups in real crystals and were not idealized and so cannot be directly shifted from one crystal to another. The results on idealized anionic groups were never formally published [26], but are given now in Table 1.

Table 1. The second-order NLO susceptibilities of some simple anionic groups * (in unit: $10^{-31}$ esu, conversion factor: 1 esu $\left.=4 \pi / 3 \times 10^{-4} \mathrm{~m} / \mathrm{V}\right)$.

\begin{tabular}{ccccccc}
\hline$\beta_{i j k}^{2 \omega}$ & $\mathbf{N O}_{2}^{-}$ & $\mathbf{N O}_{3}^{-}$ & $\mathbf{C O}_{3}^{2-}$ & $\mathbf{B O}_{3}^{3-}$ & $\mathbf{B}_{3} \mathbf{O}_{6}^{3-}$ & $\mathbf{B O}_{4}^{5-}$ \\
\hline 111 & -0.0481 & 0.7852 & 0.5911 & 0.6353 & 1.8029 & - \\
122 & -0.6288 & -0.7852 & -0.5911 & -0.6353 & -1.8029 & - \\
133 & 0.0082 & - & - & - & - & - \\
123 & - & - & - & - & - & 0.1621 \\
\hline
\end{tabular}

With the above tabulated values we calculated the SHG coefficients of crystals with reported structures containing some isolated anionic groups. The calculated results showed good agreement with experimental results whenever available (Table 2).

Table 2. Calculated SHG coefficients of selected crystals with isolated anionic groups (in unit: $10^{-9}$ esu, conversion factor: $\left.1 \mathrm{esu}=4 \pi / 3 \times 10^{-4} \mathrm{~m} / \mathrm{V}\right)$.

\begin{tabular}{ccc}
\hline Crystals & Calculated & Experimental \\
\hline $\mathrm{CaMg}_{3}\left(\mathrm{CO}_{3}\right)_{4}$ & $d_{11}^{2 \omega}=2.24$ & - \\
\hline $\mathrm{YAl}_{3}\left(\mathrm{BO}_{3}\right)_{4}$ & $d_{11}^{2 \omega}=3.30$ & 3.82 \\
\hline $\mathrm{LiCdBO}_{3}$ & $d_{11}^{2 \omega}=4.96$ & $3.0 *$ \\
\hline $\mathrm{Na}_{2} \mathrm{Ca}_{2}\left(\mathrm{CO}_{3}\right)_{3}$ & $d_{31}^{2 \omega}=2.24, d_{32}^{2 \omega}=0.21$, & - \\
\hline $\mathrm{LiK}_{2} \mathrm{BO}_{3}$ & $d_{33}^{2 \omega}=-1.31$ & - \\
\hline $\mathrm{LiNaCO}_{3}$ & $d_{21}^{2 \omega}=-0.28, d_{22}^{2 \omega}=-0.73$ & $3.0 *$ \\
\hline$\beta-\mathrm{BaB}_{2} \mathrm{O}_{4}$ & $d_{23}=0.92, d_{14}^{2 \omega}=-0.66$ & 3.82 \\
\hline $\mathrm{KBe}_{2} \mathrm{BO}_{3} \mathrm{~F}_{2}$ & $d_{11}^{2 \omega}=2.50$ & 1.17 \\
\hline $\mathrm{Be}_{2} \mathrm{BO}_{3} \mathrm{OH} \cdot \mathrm{H}_{2} \mathrm{O}$ & $d_{11}^{2 \omega}=3.78$ & - \\
\hline & $d_{11}^{2 \omega}=1.87$ & \\
\hline
\end{tabular}

${ }^{*}$ From powder SHG tests of the Kurtz-Perry method. 
One of the fascinating and practically important characteristics of the borate crystals is that within their structures, the borate groups of $\mathrm{BO}_{3}$ and $\mathrm{BO}_{4}$ can condense into larger structural units or into one- to three-dimensional skeletal structures [27]. When calculating the NLO properties of those structures, there can be different choices of the sizes for the basic structural units to obtain the microscopic SHG coefficients. For example, when calculating BBO, LBO, CBO, CLBO $\left(\mathrm{CsLiB}_{6} \mathrm{O}_{10}\right)$ [28], the basic units for the structures were chosen as $\mathrm{B}_{3} \mathrm{O}_{6}, \mathrm{~B}_{3} \mathrm{O}_{7}$, respectively. We further made the calculations of those crystals by decomposing their structural units into the smallest possible ones of $\mathrm{BO}_{3}$ and $\mathrm{BO}_{4}$. Apart from a sign change in the smallest SHG coefficient of $\mathrm{LBO}$, the final results (Table 3) showed the same level of agreement to the experimental ones [29].

Table 3. Calculated SHG coefficients of crystals' large anionic groups or skeleton borate networks (in unit: $10^{-9} \mathrm{esu}$, conversion factor: $1 \mathrm{esu}=4 \pi / 3 \times 10^{-4} \mathrm{~m} / \mathrm{V}$ ).

\begin{tabular}{cccc}
\hline Crystals & Calculated & Experimental & Calculated with $\mathbf{B O}_{3}$ and $\mathbf{B O}_{\mathbf{4}}$ \\
\hline$\beta-\mathrm{BaB}_{2} \mathrm{O}_{4}$ & $d_{11}^{2 \omega}=3.78$ & $d_{11}^{2 \omega}=3.82$ & $d_{11}^{2 \omega}=4.00$ \\
& $d_{31}^{2 \omega}=-2.24$ & $d_{31}^{2 \omega}=-2.34$ & $d_{31}^{2 \omega}=-2.77$, \\
$\mathrm{LiB}_{3} \mathrm{O}_{5}$ & $d_{32}^{2 \omega}=2.69$ & $d_{32}^{2 \omega}=2.50$ & $d_{32}^{2 \omega}=2.87$ \\
& $d_{33}^{2 \omega}=0.61$ & $d_{33}^{2 \omega}=0.14$ & $d_{33}^{2 \omega}=-0.11$ \\
\hline $\mathrm{C}_{\mathrm{S}} \mathrm{B}_{3} \mathrm{O}_{5}$ & $d_{14}^{2 \omega}=2.08$ & $d_{14}^{2 \omega}=2.79$ & $d_{14}^{2 \omega}=2.30$ \\
\hline $\mathrm{LiCsB}_{5} \mathrm{O}_{10}$ & $d_{36}^{2 \omega}=1.48$ & $d_{36}^{2 \omega}=1.77$ & $d_{36}^{2 \omega}=2.15$ \\
\hline
\end{tabular}

\section{Discussion}

After the success of the anionic group approximation for the calculation of real or potential NLO materials as shown in last section, one may draw the following conclusion from the results:

1. The anionic groups with $\pi$-conjugated electron systems, such as $\mathrm{NO}_{2}, \mathrm{NO}_{3}, \mathrm{CO}_{3}, \mathrm{BO}_{3}$, have the same level of enhanced (four times) second-order susceptibility over those $\left(\mathrm{BO}_{4}\right)$ without the $\pi$-conjugated systems.

2. The second-order susceptibilities of the condensed structural units show directional additive properties over smaller fragments, e.g., $\mathrm{B}_{3} \mathrm{O}_{6} \approx 3 \mathrm{BO}_{3}$ and $\mathrm{B}_{3} \mathrm{O}_{7} \approx \mathrm{BO}_{4}+2 \mathrm{BO}_{3}$, etc.

3. Therefore, the contributions for all the borate skeletons can be calculated by decomposition to the smallest units of $\mathrm{BO}_{3}$ and $\mathrm{BO}_{4}$.

It is also worth noting that the same level of approximation has also been applied to predict birefringence [30] and to understand the absorption cut-off at the UV side [31], both of which are also critical parameters for a NLO material.

With the above tabulated second-order NLO susceptibilities for the simple ideal anionic groups (Table 1), it should not be difficult to apply them to the recently found or proposed NLO borate or carbonate crystals [32]. For example, recently we succeeded in growing a new NLO crystal with a chemical formula of $\mathrm{K}_{3} \mathrm{~B}_{6} \mathrm{O}_{10} \mathrm{Br}$ (Figure 1) [33] into a sufficient size, which was first reported by $\mathrm{Al}$-Ama et al. [34], and it contains a borate network skeleton with an exceptionally large anionic group, $\mathrm{B}_{6} \mathrm{O}_{13}$, composed of three $\mathrm{BO}_{3}$ and three $\mathrm{BO}_{4}$ groups (Figure 2). The $\mathrm{SHG}$ coefficients of this crystal were carefully measured by the Maker Fringe method [33] and a series of mixed crystals with compositions of $\mathrm{K}_{3} \mathrm{~B}_{6} \mathrm{O}_{10} \mathrm{Br}_{1-\mathrm{x}} \mathrm{Cl}_{\mathrm{x}}$ were also grown [35]. Ab initio calculations on the mixed crystals were obtained previously and can therefore be compared with the calculation purely based on the $\mathrm{BO}_{3}$ and $\mathrm{BO}_{4}$ groups, as shown in Table 4. It is shown that absolute values of the greater $d_{22}^{2 \omega}$ of the present calculation agree with the experimental and ab initio results satisfactorily, while the smaller $d_{33}^{2 \omega}$ changes sign with the ab initio results. It will be interesting to measure the relative sign of $d_{22}^{2 \omega}$ and $d_{33}^{2 \omega}$ in the future to see which one reproduces the actual case. It is also interesting to note that the present calculation correctly reflects (with all the calculated coefficients in opposite signs) that the 
crystals with compositions of $x=0.21,0.57$ and 0.75 are actually inversion twins (Figure $1 \mathrm{~b}$ ) of the mother compounds $\mathrm{K}_{3} \mathrm{~B}_{6} \mathrm{O}_{10} \mathrm{Br}$ [35] and $\mathrm{K}_{3} \mathrm{~B}_{6} \mathrm{O}_{10} \mathrm{Cl}$ [36].

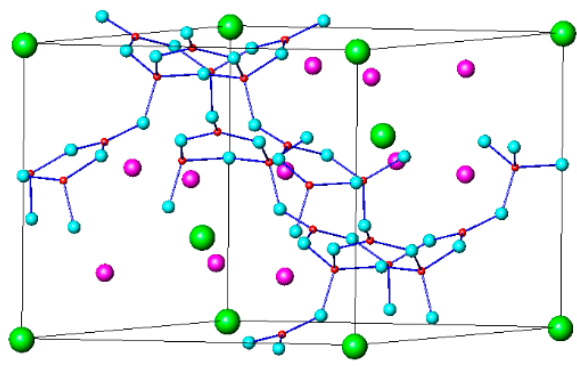

(a)

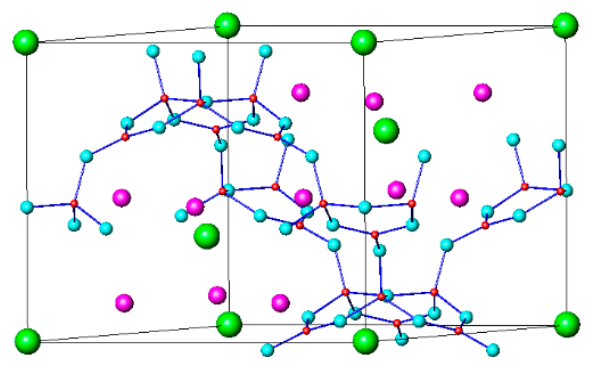

(b)

Figure 1. The crystal structure of $\mathrm{K}_{3} \mathrm{~B}_{6} \mathrm{O}_{10} \mathrm{Br}(\mathbf{a})$ and its inversion twin (b).

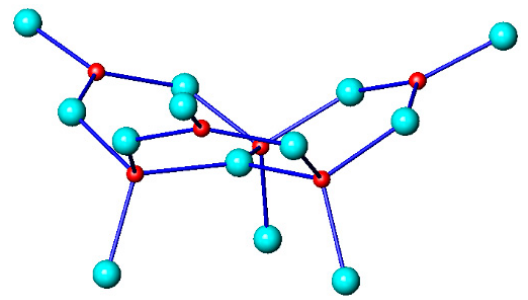

Figure 2. The $\mathrm{B}_{6} \mathrm{O}_{13}$ groups in the $\mathrm{K}_{3} \mathrm{~B}_{6} \mathrm{O}_{10} \mathrm{Br}$ structure condensed by $3 \mathrm{BO}_{3}$ and $3 \mathrm{BO}_{4}$ groups.

Table 4. Calculated SHG coefficients of crystals $\mathrm{K}_{3} \mathrm{~B}_{6} \mathrm{O}_{10} \mathrm{Br}_{1-\mathrm{x}} \mathrm{Cl}_{\mathrm{x}}$ (in unit pm/V).

\begin{tabular}{cccc}
\hline Crystals (x) & Calculated (ab initio) & Experimental & Calculated with $\mathbf{B O}_{3}$ and $\mathbf{B O}_{4}$ \\
\hline & $d_{22}^{2 \omega}=-1.247$ & $\left|d_{22}^{2 \omega}\right|=1.23$ & $d_{22}^{2 \omega}=-1.174$ \\
0 & $d_{31}^{2 \omega}=0.067$ & $\left|d_{33}^{2 \omega}\right|=0.43$ & $d_{31}^{2 \omega}=0.059$ \\
& $d_{33}^{2 \omega}=0.381$ & & $d_{33}^{2 \omega}=-0.219$ \\
\hline & $d_{22}^{2 \omega}=-1.119$ & $d_{22}^{2 \omega}=1.190$ \\
0.21 & $d_{31}^{2 \omega}=0.041$ & $d_{31}^{2 \omega}=-0.062$ \\
& $d_{33}^{2 \omega}=0.358$ & $d_{33}^{2 \omega}=0.222$ \\
\hline & $d_{22}^{2 \omega}=-1.113$ & $d_{22}^{2 \omega}=-1.179$ \\
0.35 & $d_{31}^{2 \omega}=0.036$ & $d_{31}^{2 \omega}=0.059$ \\
& $d_{33}^{2 \omega}=0.358$ & $d_{33}^{2 \omega}=-0.218$ \\
& $d_{22}^{2 \omega}=-1.110$ & $d_{22}^{2 \omega}=-1.181$ \\
0.47 & $d_{31}^{2 \omega}=0.035$ & $d_{31}^{2 \omega}=0.060$ \\
& $d_{33}^{2 \omega}=0.357$ & $d_{33}^{2 \omega}=-0.221$ \\
\hline & $d_{22}^{2 \omega}=-1.103$ & $d_{22}^{2 \omega}=1.193$ \\
0.57 & $d_{31}^{2 \omega}=0.031$ & $d_{31}^{2 \omega}=-0.063$ \\
& $d_{33}^{2 \omega}=0.360$ & $d_{33}^{2 \omega}=0.229$ \\
& $d_{22}^{2 \omega}=-1.095$ & $d_{22}^{2 \omega}=1.196$ \\
0.75 & $d_{31}^{2 \omega}=0.026$ & $d_{31}^{2 \omega}=-0.064$ \\
& $d_{33}^{2 \omega}=0.363$ & $d_{33}^{2 \omega}=0.233$ \\
\hline & $d_{22}^{2 \omega}=-1.078$ & $d_{22}^{2 \omega}=-1.182$ \\
& $d_{31}^{2 \omega}=0.024$ & $d_{31}^{2 \omega}=0.060$ \\
& $d_{33}^{2 \omega}=0.364$ & $d_{33}^{2 \omega}=-0.226$ \\
\hline
\end{tabular}

\section{Materials and Methods}

We firstly applied the CNDO program to obtain the ground $|g\rangle$ and excited states $|n\rangle$ of the anionic groups in ideal geometries as listed in the footnotes of Table 1. Then the microscopic second 
order susceptibilities $\beta_{i j k}^{2 \omega}$ (Table 1) of the idealized anionic groups were obtained by Equation (1). The macroscopic NLO coefficients of certain crystals can be obtained by the geometric superposition of the second order susceptibilities of the anionic groups in unit cell with Equation (3), and the refractive indices of the crystal were assumed to a mean value of 1.65 whenever they were unknown.

\section{Conclusions}

Anionic group approximation has been shown to give good agreements and even success in predicting new nonlinear optical crystals in borate compounds. Similar results can be expected with the present tabulation of the calculated second-order susceptibilities for the carbonate and nitrate groups that have been drawing attention in recent years.

Acknowledgments: This work was supported by the National Instrumentation Program (No. 2012YQ120048).

Conflicts of Interest: The author declares no conflict of interest.

\section{References}

1. Franken, P.A.; Hill, A.E.; Peters, C.W.; Weinreich, G. Generation of Optical Harmonics. Phys. Rev. Lett. 1961, 7, 118-119. [CrossRef]

2. Giordmaine, J.A. Mixing of light beams in Crystals. Phys. Rev. Lett. 1962, 8, 19-20. [CrossRef]

3. Boyd, G.D.; Kasper, H.; McFee, J.H. Linear and nonlinear optical properties of $\mathrm{AgGaS}_{2}, \mathrm{CuGaS}_{2}$ and $\mathrm{CuInS}$, and theory of the wedge technique for measurement of nonlinear coefficients. IEEE J. Quantum Electron. 1971, QE-7, 563-573. [CrossRef]

4. Byer, R.L. Nonlinear optical phenomena and materials. Annu. Rev. Mater. Sci. 1974, 4, 147-190. [CrossRef]

5. Dmitriev, V.G.; Gurzdyan, G.G.; Nokogosyan, D.N. Handbook of Nonlinear Optical Crystals; Springer: Berlin, Germany, 1999.

6. Armstrong, J.A.; Bloembergen, N.; Ducuing, J.; Pershan, P.S. Interactions between Light Waves in a Nonlinear Dielectric. Phys. Rev. 1962, 127, 1918-1939. [CrossRef]

7. Lax, B.; Mavroides, J.G.; Edwards, D.F. Nonlinear Interband and Plasma Effects in Solids. Phys. Rev. Lett. 1962, 8, 166-168. [CrossRef]

8. Levine, B.F. Bond-Charge Calculation of Nonlinear Optical Susceptibilities for Various Crystal Structures. Phys. Rev. B 1973, 7, 2600-2626. [CrossRef]

9. Chemla, D.S.; Oudar, J.L.; Jerphagnon, J. Origin of the second-order optical susceptibilities of crystalline substituted benzene. Phys. Rev. B 1975, 12, 4534-4546. [CrossRef]

10. Davydov, B.L.; Derkacheva, L.D.; Dunina, V.V.; Zhabotinskii, M.E.; Zolin, V.F.; Koreneva, L.G.; Samokhina, M.A. Connection Between Charge Transfer and Laser Second Harmonic Generation. JETP Lett. 1972, 12, 16-18.

11. Oudar, J.L.; Chemla, D.S. Hyperpolarizabilities of the nitroanilines and their relations to the excited state dipole moment. J. Chem. Phys. 1977, 66, 2664-2668. [CrossRef]

12. Zyss, J. Engineering new organic crystals for nonlinear optics: From molecules to oscillator. J. Phys. D Appl. Phys. 1993, 26, B198-B207. [CrossRef]

13. Chen, C.T. An ionic grouping theory of the electro-optical and nonlinear optical effects of crystals (I)-A theoretical calculation of electro-optical and second optical harmonic coefficients of barium titanate crystals based on a deformed oxygen-cctahedra. Acta Phys. Sin. 1976, 25, 146-161.

14. Chen, C.T. An ionic grouping theory of the electro-optical and nonlinear optical effects of crystals (II)-A theoretical calculation of the second harmonic optical coefficients of the lithium iodate crystal based on a highly deformed oxygen-octahedra model. Acta Phys. Sin. 1977, 26, 124-132.

15. Chen, C.T. An ionic grouping theory of the electro-optical and nonlinear optical effects of crystals (III)-A theoretical calculation of the electro-optical and optical second harmonic coefficients of $\mathrm{LiNbO}_{3}, \mathrm{LiTaO}_{3}$, $\mathrm{KNbO}_{3}$ and $\mathrm{BNN}$ crystals based on a deformed oxygen-octahedra ionic grouping model. Acta Phys. Sin. $1977,26,486-499$.

16. Chen, C.T. A localized quantal theoretical treatment based on anionic coordination polyhedron model for the EO and SHG effects in crystals of the mixed types. Sci. Sin. 1979, 22, 756-776. 
17. Chen, C.T.; Liu, G.Z. Recent Advances in Nonlinear Optical and Electro-Optical Materials. Annu. Rev. Mater. Sci. 1986, 16, 203-243. [CrossRef]

18. Chen, C.T.; Wu, B.C.; Jiang, A.D.; You, G.M. A new ultraviolet SHG crystal- $\beta-\mathrm{BaB}_{2} \mathrm{O}_{4}$. Sci. China Ser. B Chem. Biol. Agric. Med. Earth Sci. 1985, 28, 235-243.

19. Pople, J.A.; Santry, D.P.; Segal, G.A. Approximate Self-Consistent Molecular Orbital Theory. I. Invariant Procedures. J. Chem. Phys. 1965, 43, S129-S135. [CrossRef]

20. Li, R.K.; Chen, C.T. The theoretical calculation of SHG coefficients of $\beta-\mathrm{BaB}_{2} \mathrm{O}_{4}$ crystal. Acta Phys. Sin. 1985, 34, 823-827.

21. Chen, C.T.; Wu, Y.C.; Li, R.K. The relationship between the structural type of anionic group and SHG effect in Boron-Oxygen compounds. Chin. Phys. Lett. 1985, 2, 389-392.

22. Chen, C.T.; Wu, Y.C.; Li, R.K. The anionic group theory of the non-linear optical effect and its applications in the development of new high-quality NLO crystals in the borate series. Int. Rev. Phys. Chem. 1989, 8, 65-91. [CrossRef]

23. Chen, C.T.; Wu, Y.C.; Li, R.K. The development of new NLO crystals in the borate series. J. Cryst. Growth 1990, 99, 790-798. [CrossRef]

24. Chen, C.T.; Wu, Y.C.; Jiang, A.D.; Wu, B.C.; You, G.M.; Li, R.K.; Lin, S.J. New nonlinear-optical crystal: $\mathrm{LiB}_{3} \mathrm{O}_{5}$. J. Opt. Soc. Am. B 1989, 6, 616-621. [CrossRef]

25. Wu, Y.C.; Sasaki, T.; Nakai, S.; Yokotani, A.; Tang, H.G.; Chen, C.T. $\mathrm{CsB}_{3} \mathrm{O}_{5}$ : A new nonlinear optical crystal. Appl. Phys. Lett. 1993, 62, 2614-2615. [CrossRef]

26. Li, R.K. Searching for Ultraviolet Inorganic Nonlinear Optical Crystals. Ph.D. Thesis, Fujian Institute on the Structure of Matter, Chinese Academy of Sciences, Fujian, China, 1988.

27. Wells, A.F. Structural Chemistry, 5th ed.; Oxford University Press: Oxford, UK, 1984.

28. Mori, Y.; Kuroda, I.; Nakajima, S.; Sasaki, T.; Nakai, S. New nonlinear optical crystal: Cesium lithium borate. Appl. Phys. Lett. 1995, 67, 1818-1820. [CrossRef]

29. Chen, C.T.; Sasaki, T.; Li, R.K.; Wu, Y.C.; Lin, Z.S.; Mori, Y.; Hu, Z.G.; Wang, J.Y.; Uda, S.; Yoshimura, M.; et al. Nonlinear Optical Borate Crystals; Wiley-VCH: Weinheim, Germany, 2012.

30. Li, R.K. On the calculation of refractive indices of borate crystals based on group approximation. Z. Kristallogr. 2013, 228, 526-531. [CrossRef]

31. Li, R.K. The interpretation of UV absorption of borate glasses and crystals. J. Non-Cryst. Solids 1989, 111, 199-204.

32. Tran, T.T.; Yu, H.W.; Rondinelli, J.M.; Poeppelmeier, K.R.; Halasyamani, P.S. Deep Ultraviolet Nonlinear Optical Materials. Chem. Mater. 2016, 28, 5238-5258. [CrossRef]

33. Xia, M.J.; Xu, B.; Li, R.K. Growth and nonlinear optical properties of $\mathrm{K}_{3} \mathrm{~B}_{6} \mathrm{O}_{10} \mathrm{Br}$ crystal. J. Cryst. Growth 2014, 404, 65-68. [CrossRef]

34. Al-Ama, A.G.; Belokoneva, E.L.; Stefanovich, S.Y.; Dimitrova, O.V.; Mochenova, N.N. Potassium bromo-borate $\mathrm{K}_{3}\left[\mathrm{~B}_{6} \mathrm{O}_{10}\right] \mathrm{Br}-\mathrm{A}$ new nonlinear optical material. Crystallogr. Rep. 2006, 51, 225-230.

35. Xia, M.J.; Hou, Z.Y.; Yang, Y.; Xu, B.; Liu, L.J.; Wang, X.Y.; Lin, Z.S.; Li, R.K.; Chen, C.T. Chemical engineering of mixed halide hexaborates as nonlinear optical materials. RSC Adv. 2016, 6, 107810-107815. [CrossRef]

36. Wu, H.; Pan, S.; Poeppelmeier, K.R.; Li, H.; Jia, D.; Chen, Z.; Fan, X.; Yang, Y.; Rondinelli, J.M.; Luo, H. $\mathrm{K}_{3} \mathrm{~B}_{6} \mathrm{O}_{10} \mathrm{Cl}$ : A New Structure Analogous to Perovskite with a Large Second Harmonic Generation Response and Deep UV Absorption Edge. J. Am. Chem. Soc. 2011, 133, 7786-7790. [CrossRef] [PubMed]

(C) 2017 by the author; licensee MDPI, Basel, Switzerland. This article is an open access article distributed under the terms and conditions of the Creative Commons Attribution (CC BY) license (http:/ / creativecommons.org/licenses/by/4.0/). 